\title{
Medicine in China
}

\section{Population Control in China}

\author{
EVELYN M. ADEY
}

British Medical fournal, 1974, 2, 548-550

\begin{abstract}
Among the visual memories of our time in China one of the most vivid is the never-ending streams of cyclists moving along the tree-lined roads in the big cities. The bicycle is a highly prized possession in a Chinese household-and almost always it is the usual transport for the family. Many of the bicycles we saw were pedalled by a young man with one child in a bamboo seat on the crossbar and his wife carrying the second child seated side-saddle on the carrier over the rear wheel.
\end{abstract}

\section{Two-child Families}

The streams of families on bicycles were just one example of the fact that in China today the usual number of children is two. Families out for the day at the Great Wall of China, or at the Peking Zoo, or celebrating May Day, watching traditional lion-dog dances-everywhere we saw young couples with one or two children, never more.

This is a radical change in attitude achieved within the space of one generation. Up to the time of the Communist victory in China infant and child mortality had been high, encouraging large families; so that in general the birth rate was as high as anywhere else in the East, averaging perhaps $50 / 1,000$.

When the Communists took over control in 1949 they had no reason to worry about population growth-and in any case Marxist theory had nothing to say on the subject. The attitude at that time was that the larger the population, the larger the potential national wealth. In 1953, however, there was a national census which put the population at 582,603,417 (not counting 12 million Chinese living overseas and $7 \frac{1}{2}$ million in Taiwan); and before long the merits of birth control began to be discussed in official publications. By 1957 it had become official Government policy that the birth rate should be reduced.

However, in the Great Leap Forward of 1958 (when a huge national campaign set about modernizing China's industry and agriculture) a large population was once again seen as advantageous and the policy was shelved. The third and (so far) final switch came in 1962, when after a poor harvest and an economic crisis the merits of a controlled birth rate again became apparent. For more than 10 years family planning has been part of the national policy for health, and this policy seems to have been supported by the people.

Medical Centre, Borehamwood, Herts

EVELYN M. ADEY, M.B., M.R.C.G.P., General Practitioner

\section{Ten Years' Achievements}

Charts of the birth rate are to be seen, prominently displayed, in many commune hospitals and health stations. One agricultural commune near Shanghai, for example, had a graph showing a fall from 45 per 1,000 in 1963 to 10.4 per 1,000 in 1972 (the rate in England and Wales was 14.8/1,000.). No national statistics seemed to be available, but there is general agreement among western observers that the rate of population growth is now far slower than in any other country outside Europe. How has this been achieved?

\section{Education and Sexual Morality}

The first line of attack has been health education. This takes two main themes: firstly, that the state needs a stable population (fig. 1), and secondly, that women can be equal only when they are freed from endless childbearing. It seemed to us that the probable reason that people comply so readily with the state's wishes is their gratitude for freedom from starvation and disease. The full force of this can perhaps be understood only by a nation which has really known starvation.

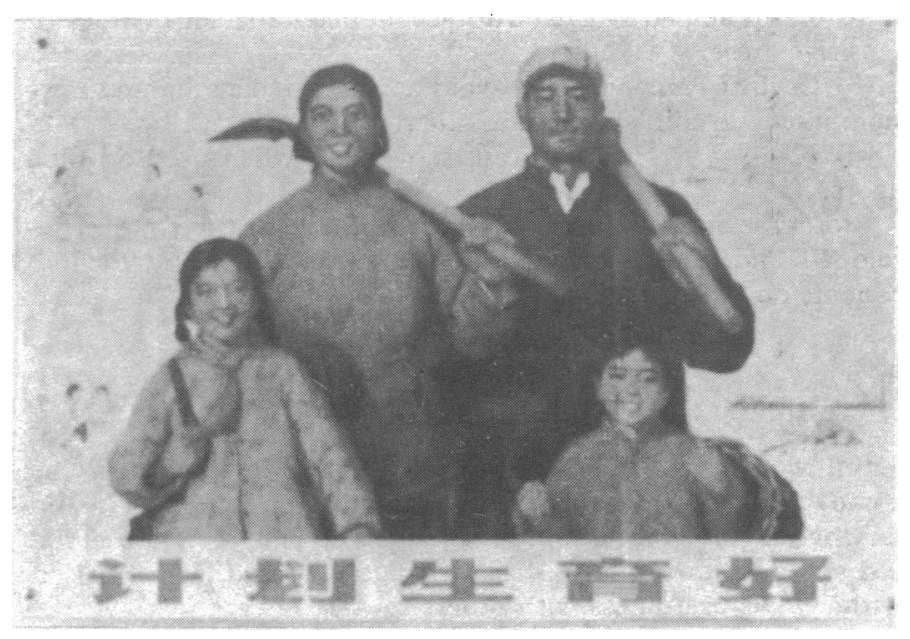

FIG. 1-Poster on wall of country health station urging limitation of family size.

The equality of women is taken very seriously, with specific government directives against their exploitation. We found that in primary schools children are told stories about heroism by women during the war of liberation, while magazines contain articles describing women whose self-reliance and determination had enabled them to prove they could do 
a man's job. Women are unlikely to throw away the freedom they have obtained for the sake of more children.

We found it perplexing that Chinese society both strongly disapproves of premarital sexual activity and yet at the same time urges young men and women to delay marriage until their late 20s. This means that most young people are celibate for many years. As we learnt more of the current moral attitudes in China we found this sexual continence easier to understand.

China has no tradition of romantic, Western love, and virginity has always been highly prized. There has never been any suggestion that the liberation of Chinese women might extend to sexual mores.

From the age of 4 , when a child enters kindergarten-and often earlier in homes and nurseries-the children are taught to value the thoughts and attitudes of postrevolutionary China. The one attribute that was clearly and consistently rewarded was "morality" or "good character." Even though they do sit exams in specific subjects I was assured that advancement in a job or position on a committee was based primarily on the character of the applicant, not on examination results. When $I$ asked about the management of dissenters I was told that the dissenter would discuss his problems with the revolutionary committee and they would help him understand the situation more clearly-not very different from group therapy. This process is continued into adult life, when everyone spends some time on political thought, self examination, and discussions. This may amount to an hour a day in factories or an afternoon a week for doctors in central hospitals.

There is, then, a strong climate of opinion in favour of premarital chastity-supported by slogans such as "making love is a mental disease which wastes time and energy." Add to this the conformist tendency which seems part of the Chinese national character and it becomes possible to see how the millions of teenage Red Guards could roam the country during the cultural revolution, living and sleeping together for months on end, with no suggestion of sexual misbehaviour.

Syphilis is one of the diseases that is now said to be extinct. Certainly we saw and heard nothing about venereal disease in the course of medical discussions, and we were told that there is no provision of contraceptives for unmarried persons. I believe that extramarital pregnancy is indeed rare and that if it occurs the couple are encouraged to marry.

\section{Contraception After Marriage}

At marriage couples are given detailed advice about contraception and this is reinforced at commune or factory meetings and by home visits by barefoot doctors. Condoms and foam pessaries are readily available at very low prices in local shops. I was told that they were widely used but no figures were available.

The intrauterine device is used only in parous women. The number of people using this method seems to vary from place to place but on the whole its popularity is waning in favour of oral contraception. The device in common use in the commune hospitals we visited was a steel ring (fig. 2). We were told that it had a failure rate of about 8 pregnancies $/ 100$ woman years. Larger hospitals are now using plastic coils such as the "flower of Canton." These were as effective as I.U.D.s in use in Britain; I am sure they will supersede the earlier coil but for the moment economics prevent their wider use. I.U.D.s are inserted in any hospital, including the commune hospital, but not in health stations. They are free, as are oral contraceptives.

Oral contraception is becoming increasingly popular. The Chinese have been doing a lot of research into low dose

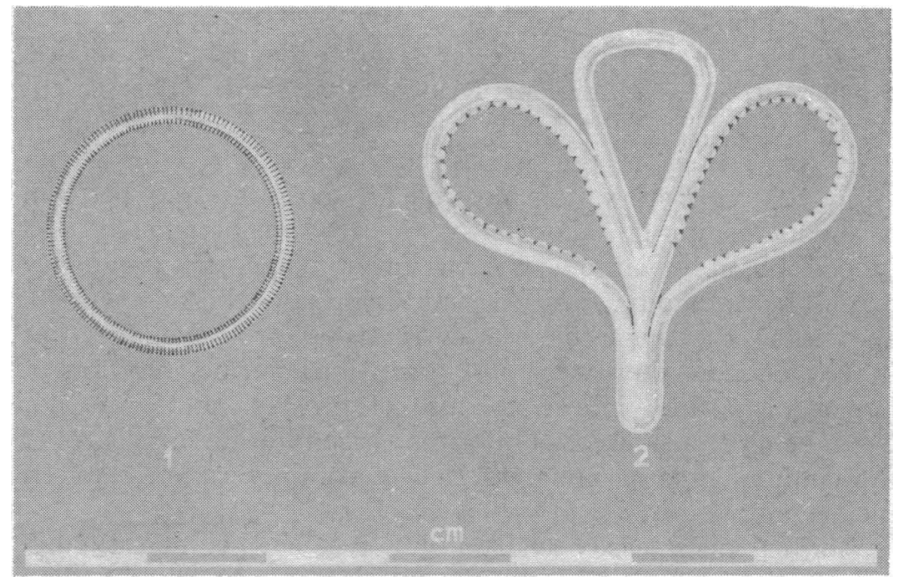

FIG. 2-Stainless steel spiral (1) used as I.U.D. This is being superseded by plastic devices such as (2), the "flower of Canton."

pills, postcoital pills, pills for men, and so on. Most of this has not yet come to fruition. In common use are: "Pill 1," "Pill 2," a once-a-month pill, and a monthly injection. Pills 1 and 2 are very similar to our combined preparations, Pill 2 being of low oestrogen dosage. The once-monthly pill is also a combined oestrogen-progesterone pill, containing about five times the dose of hormones found in Pill 1. This pill is taken on the fifth day of the cycle and apparently affords about $88 \%$ protection. The monthly depot injection is of similar effectiveness. I was told that the necessarily larger dose of the single preparations produced relatively severe side effects-fairly intense nausea, vomiting, and malaise. It also produces poor cycle control, sometimes causing prolonged amenorrhoea or breakthrough bleeding.

Oral contraceptives are supplied to women by the barefoot doctors and factory doctors-and it seems some of the responsibility for remembering the supplies is taken by the barefoot doctors as well as the patients. Follow-up of their patients to make sure they are taking their medicines is an essential part of the barefoot doctors' job.

None of the Chinese cardiologists or gynaecologists we met had found any evidence of thrombosis due to oral contraceptives. Venous thrombosis seems rare in China, and the Chinese seemed to be mystified by our concern about a thrombotic risk from the pill.

\section{Abortion}

No-one we met was able to give any national statistics on abortion. In the Capital Hospital in Peking (550 beds) we were told that the gynaecologists did "about 10 a day"; in the slightly larger Provincial Hospital in Kwangchow the estimate was 15-20 daily. At the hospital in one of the communes in which there were about 600 births per annum, we were told that 296 abortions had been done in the previous year.

The number of abortions must be high, since there is no reason to doubt the very low birth rates quoted in all the communes we visited (between 10 and $15 / 1,000$ in a population with most women still of childbearing age) yet many women were using I.U.D.s and other forms of contraception with a high failure rate.

Abortion is done for all the usual medical reasons, but the main indication seems to be unintended pregnancy in women who already have two children. I was assured that limitation of family size is not compulsory but that most women 
preferred the freedom to work outside the home to the rigours of a large family.

Abortion in the first trimester is normally done by suction evacuation, as an outpatient, with no anaesthetic. The patient occasionally has an analgesic or she may be given acupuncture. Since none of the legal procedures required in Britain apply to termination it is possible in most cases to perform a suction-aspiration abortion very early in pregnancy, and indeed possibly without waiting for a diagnostic pregnancy test. The methods used for mid-trimester abortion varied. In Peking the gynaecologists were using prostaglandins but in Kwangchow they were still using intrauterine injection of hypertonic saline; indeed the use of prostaglandins was not even being considered. This emphasized to me the size of the country and the apparent lack of communication between major centres.

Sterilization is easily available for men and women, though I gather that there is a certain amount of reluctance among men to have the operation. Again I was not able to get accurate figures but was told that sterilization is quite common in women with two children.

\section{Reasons for Success}

The decentralized system for delivering medicine in China means that the whole population has access to contraceptive advice and to abortions and sterilizations. However, experience throughout the world has shown that simple provision of contraceptive technology by itself does little to affect population growth. The success of China's policy is that it is unequivocal and direct-there are no warring factions as there are in Britain. The policy is based on the acceptance by the people of the three main principles: no sex before marriage, only two children to the family, and abortion for any unintended pregnancies.

So far as we could see, these messages are constantly repeated by the posters and in the political thought sessions that are a major feature of life in China. Whenever we discussed the concepts and methods with doctors, workers, or patients we were impressed by their positive attitude. What would in the West be thought of as severe restrictions on individual liberty are evidently not seen in that light in China.

\title{
Today's Treatment
}

\section{Blood and Neoplastic Diseases}

\section{Megaloblastic Anaemia}

\author{
A. V. HOFFBRAND, A. LAVOIE
}

British Medical fournal, 1974, 2, 550-553

\section{Introduction}

Megaloblastic anaemia is one of the most satisfactory of all disorders to treat. A patient with a life-threatening anaemia can often be restored to full health. Nevertheless, correct management depends not only on recognizing that megaloblastic anaemia is present, but also on diagnozing its underlying cause, and failure of full investigation and of adequate follow-up account for most cases of incorrect therapy or subsequent relapse. Early clinical or haematological signs of vitamin $B_{12}$ or folate deficiency should always be taken seriously; otherwise the anaemia will progress and irreversible neurological damage may also occur.

\section{Diagnosis}

Though megaloblastic anaemia may be suspected clinically because of anaemia, jaundice, glossitis, neuropathy, or presence of a disease known to predispose to vitamin $B_{12}$ or folate deficiency, ultimately the diagnosis depends on the laboratory findings. Megaloblastosis is suggested by macrocytes and hyper-

\footnotetext{
Department of Haematology, Royal Postgraduate Medical School, London W12 0HS

A. V. HOFFBRAND, D.M., M.R.C.P., Senior Lecturer (Present appointment: Professor of Haematology, Royal Free Hospital, London, NW3 2QG). A. LAVOIE, M.D., Research Fellow in Haematology (Supported by the A. LAVOIE, M.D., Research Fellow in
Medical Research Council of Canada)
}

segmented polymorphs in a peripheral blood film and is confirmed by characteristic changes in the bone marrow. The introduction of electronic red cell counters has facilitated early recognition of macrocytosis and any patient found to have a mean corpuscular volume (M.C.V.) greater than $100 \mathrm{fl}$ should be suspected of vitamin $B_{12}$ or folate deficiency even in the absence of anaemia. Other causes of macrocytosis include haemolytic anaemia, blood regeneration, liver disease, alcoholism, myxoedema, aplastic anaemia, myeloma, sideroblastic anaemia, and leucoerythroblastic anaemia. The higher the M.C.V. the more likely is megaloblastic anaemia to be present. But when iron deficiency and megaloblastic anaemia are combined the M.C.V. may be normal; nevertheless, the blood and bone marrow still show some of the morphological characteristics of megaloblastic anaemia.

\section{Causes}

The anaemia may be due to vitamin $B_{12}$, folate deficiency, or rarely another cause. Vitamin $B_{12}$ is present only in foods of animal origin and is absorbed through the terminal ileum, a process mediated by gastric intrinsic factor and limited to a few microgrammes daily. Adult daily requirements are about $2-3 \mu \mathrm{g}$ and stores 3-4 mg, sufficient for a few years. In Britain deficiency is usually due to malabsorption and pernicious anaemia is by far the most important cause of this. Resection of the stomach or ileum, a stagnant-loop, or some other small intestinal disease are less frequent causes. Veganism commonly leads to vitamin $\mathrm{B}_{12}$ deficiency in areas of Britain where there are many Hindu immigrants.

Folate is present in both vegetable and animal foods, particularly in greens and liver, but, unlike vitamin $B_{12}$, folate is 